\title{
Seedling Growth Is Similar under Supplemental Greenhouse Lighting from High-pressure Sodium Lamps or Light-emitting Diodes
}

\author{
Brian R. Poel ${ }^{1}$ and Erik S. Runkle ${ }^{2,3}$ \\ Department of Horticulture, Michigan State University, 1066 Bogue Street, \\ East Lansing, MI 48824
}

Additional index words. bedding plants, controlled environments, LEDs, light quality

\begin{abstract}
Light-emitting diodes (LEDs) have the potential to replace high-pressure sodium (HPS) lamps as the main delivery method of supplemental lighting (SL) in greenhouses. However, few studies have compared growth under the different lamp types. We grew seedlings of geranium (Pelargonium $\times$ hortorum), pepper (Capsicum annuum), petunia (Petunia $\times$ hybrida), snapdragon (Antirrhinum majus), and tomato (Solanum lycopersicum) at $20{ }^{\circ} \mathrm{C}$ under six lighting treatments: five that delivered a photosynthetic photon flux density $(P P F D)$ of $90 \mu \mathrm{mol} \cdot \mathrm{m}^{-2} \cdot \mathrm{s}^{-1}$ from HPS lamps (HPS $\left._{90}\right)$ or LEDs [four treatments composed of blue $(B, 400-500 \mathrm{~nm})$, red $(\mathrm{R}, 600$ $700 \mathrm{~nm}$ ), or white LEDs] and one that delivered $10 \mu \mathrm{mol} \cdot \mathrm{m}^{-2} \cdot \mathrm{s}^{-1}$ from HPS lamps $\left(\right.$ HPS $\left._{10}\right)$, which served as a control with matching photoperiod. Lamps operated for 16 $h \cdot d^{-1}$ for 14 to 40 days, depending on cultivar and season. The LED treatments defined by their percentages of $B$, green $(G, 500-600 \mathrm{~nm})$, and $R$ light were $B_{10} R_{90}, B_{20} R_{80}, B_{10} G_{5} R_{85}$, and $B_{15} G_{5} R_{80}$, whereas the HPS treatments emitted $B_{6} G_{61} R_{33}$. Seedlings of each cultivar grown under the $90 \mu \mathrm{mol} \cdot \mathrm{m}^{-2} \cdot \mathrm{s}^{-1} \mathrm{SL}$ treatments had similar dry shoot weights and all except pepper had a similar plant height, leaf area, and leaf number. After transplant to a common environment, geranium 'Ringo Deep Scarlet' and petunia 'Single Dreams White' grown under HPS $_{90}$ flowered 3 days earlier than those grown under HPS $_{10}$, but flowering time was not different from that in LED treatments. There were no consistent differences in morphology or subsequent flowering among seedlings grown under HPS $_{90}$ and LED SL treatments. The inclusion of white light in the LED treatments played an insignificant role in growth and development when applied as SL with the background ambient light. The LED fixtures in this study consumed substantially less electricity than the HPS lamps while providing the same $P P F D$, and seedlings produced were of similar quality, making LEDs a suitable technology option for greenhouse SL delivery.
\end{abstract}

Annual bedding plants is the largest segment of floriculture crop production in the United States, with a reported wholesale value of $\$ 1.29$ billion in 2015 for operations with $>\$ 100,000$ in sales in the 15 states surveyed (USDA, 2016). To coordinate production cycles and have finished crops ready for spring markets, bedding plants (and other floriculture crops) are grown from seeds and

Received for publication 12 Sept. 2016. Accepted for publication 18 Jan. 2017.

We gratefully acknowledge support by the USDA National Institute of Food and Agriculture's Specialty Crop Research Initiative, the USDA-ARS Floriculture and Nursery Research Initiative, C. Raker and Sons for donation of plant material, Philips for donation of LED fixtures, and Nate DuRussel for technical assistance. We also thank Jennifer Boldt and Ryan Warner for their critical review of this manuscript.

This work was supported by the USDA National Institute of Food and Agriculture, Hatch project 192266.

${ }^{1}$ Graduate Student.

${ }^{2}$ Professor and Floriculture Extension Specialist. ${ }^{3}$ Corresponding author. E-mail: runkleer@msu. edu. cuttings in controlled-environment greenhouses at high densities during winter and spring. During this period, the mean daily light integral (DLI) received outdoors in northern latitudes (e.g., $>35^{\circ} \mathrm{N}$ lat.) is as low as 5 to $10 \mathrm{~mol} \cdot \mathrm{m}^{-2} \cdot \mathrm{d}^{-1}$ (Korczynski et al., 2002). Inside a greenhouse, DLI can be reduced by $50 \%$ or more by the glazing, structural components, and other obstructions (Fisher and Runkle, 2004). During the propagation phase, increasing DLI when it is $\leq 10$ to $12 \mathrm{~mol} \cdot \mathrm{m}^{-2} \cdot \mathrm{d}^{-1}$ can increase shoot biomass, rate of development, rooting, and plant quality while reducing flowering time (Currey et al., 2012; Lopez and Runkle, 2008; Pramuk and Runkle, 2005; Torres and Lopez, 2011). DLI can be increased during periods of low DLI with SL, which is usually provided by HPS lamps.

LEDs have shown promise as SL in horticultural applications (Hernandez and Kubota, 2014; Randall and Lopez, 2014, 2015). Compared with traditional HPS lighting, LEDs potentially have a greater electrical efficacy and longer life span (Nelson and Bugbee, 2014). For conventional lamps, on/ off cycles reduce the lifetime of filaments and igniters, and electronic ballasts must be periodically replaced (Morrow, 2008). Additionally, by emitting specific wavebands of light, LEDs have the potential to provide a light spectrum that maximizes light absorption for growth and development by targeting the absorption peaks of chlorophyll and other important photobiological pigments (Mitchell et al., 2015)

The addition of ancillary wavebands of light to monochromatic LEDs has been shown to elicit photosynthetic and morphological responses in sole-source lighting (SSL) experiments. Cucumber (Cucumis sativus 'Hoffmann's Giganta') seedlings grown under red (R, 600-700 $\mathrm{nm}$ ) light alone from LEDs developed leaves that had reduced carbon dioxide $\left(\mathrm{CO}_{2}\right)$ assimilation mediated by decreased stomatal conductance and stomatal count compared with seedlings grown under $7 \%$ blue (B, 400-500 nm) $+93 \% \mathrm{R}$ (Hogewoning et al., 2010). Similarly, Goins et al. (1997) reported wheat (Triticum aestivum 'USU-Super Dwarf') grown under R + $10 \% \mathrm{~B}$ (from B fluorescent lamps) had more than twice as much $\mathrm{CO}_{2}$ uptake, and dry weight was $153 \%$ greater than that of plants grown under $\mathrm{R}$ alone. Wollaeger and Runkle (2014) reported that partial substitution of $\mathrm{R}$ or green $(\mathrm{G}, 500-600 \mathrm{~nm})$ light with $\mathrm{B}$ decreased seedling height and leaf expansion. Impatiens (Impatiens walleriana 'SuperElfin XP Red'), tomato (Solanum lycopersicum 'Early Girl'), and salvia (Salvia splendens 'Vista Red') seedlings were grown under LEDs at a PPFD of $160 \mu \mathrm{mol} \cdot \mathrm{m}^{-2} \cdot \mathrm{s}^{-1}$ and the light quality was $100 \% \mathrm{R}$ or $\mathrm{R}$ with an increasing percentage of $\mathrm{B}$. Those grown under at least $25 \% \mathrm{~B}$ were shorter and had decreased leaf area compared with seedlings grown under $\mathrm{R}$ alone (Wollaeger and Runkle, 2014).

Few studies have been published on how light quality of SL influences plant growth in greenhouses. Randall and Lopez (2014) reported decreased height of vinca (Catharanthus roseus 'Titan Punch'), celosia (Celosia plumosa 'Fresh Look Gold'), impatiens 'Dazzler Pearl Blue', petunia (Petunia $\times$ hybrida 'Plush Blue'), marigold (Tagetes patula 'Bonanza Flame'), and viola (Viola $\times$ wittrockiana 'Mammoth Big Red') seedlings grown under $15 \% \mathrm{~B}+85 \% \mathrm{R}$ light from LEDs compared with those grown under HPS $\mathrm{SL}$ at a $P P F D$ of $160 \mu \mathrm{mol} \cdot \mathrm{m}^{-2} \cdot \mathrm{s}^{-1}$. However, there were no differences in height for the same species grown under $30 \% \mathrm{~B}+70 \% \mathrm{R}$ LED SL compared with those grown under $15 \% \mathrm{~B}+85 \% \mathrm{R}$ LED SL. In the production of vegetable transplants, the amount of B in SL for a desired growth habit remains unclear. Hernandez and Kubota (2014) measured growth and development responses of cucumber seedlings grown under increasing B: $\mathrm{R}$ ratios from LEDs under average DLIs of 5.2 and $16.2 \mathrm{~mol} \cdot \mathrm{m}^{-2} \cdot \mathrm{d}^{-1}$. At the low DLI, chlorophyll concentration increased as the B: $\mathrm{R}$ ratio increased, but dry weight, leaf area, and leaf number decreased. In contrast, at the higher DLI, B:R treatments had no effect on the same metrics.

For LEDs to achieve their potential as a delivery method for SL, seedlings and 
finished plants must be of a quality equal to or greater than that of those produced under HPS SL and be at least as cost-effective. Our objective was to quantify the effects of SL from four different commercial LED fixtures and HPS lamps on growth and subsequent development of seedlings of popular bedding plant crops. We postulated that relatively small changes to the radiation spectrum of SL, regardless of lamp type, would have little or no effect on seedling growth and subsequent flowering.

\section{Materials and Methods}

Plant material. Seeds of geranium [Pelargonium $\times$ hortorum 'Pinto Premium Salmon' ('PPS') and 'Ringo 2000 Deep Scarlet'('RDS')], pepper (Capsicum annuum 'Long Red Slim Cayenne'), petunia 'Single Dreams White' ('SDW') and 'Wave Misty Lilac' ('WML'), snapdragon (Antirrhinum majus 'Montego Yellow'), and tomato 'Supersweet' were sown into 128-cell plug trays $(2.7 \times 2.7 \mathrm{~cm} ; 12.0-\mathrm{mL}$ volume $)$ at a commercial greenhouse (C. Raker and Sons, Inc., Litchfield, MI). Plants were transported to the Plant Science Research Greenhouses at Michigan State University (MSU, East Lansing, MI), 1 (replication 1), 9 (replication 2), or 8 days (replication 3) after seed sow. Seedlings were held longer at the propagator for replications 2 and 3 to improve germination uniformity. For each cultivar, six 128cell trays were cut in half and the 12 half trays were randomly assigned to six lighting treatments in adjacent greenhouse sections. Seedling trays of each cultivar were placed at about the same position in each section and rotated systematically every 2 days to minimize positional effects in the greenhouses. Seedlings were irrigated as necessary with water-soluble fertilizer providing (in $\mathrm{mg} \cdot \mathrm{L}^{-1}$ ) $60 \mathrm{~N}, 23 \mathrm{P}, 60 \mathrm{~K}, 27.7 \mathrm{Ca}, 4.6 \mathrm{Mg}, 1.3 \mathrm{Fe}, 0.6$ $\mathrm{Mn}, 0.6 \mathrm{Zn}, 0.6 \mathrm{Cu}, 0.4 \mathrm{~B}$, and 0.1 Mo (MSU Plug Special; GreenCare Fertilizers, Inc., Kankakee, IL).

Environmental conditions. The six nearly identical greenhouse sections used for this research were oriented west to east and measured $4.0 \mathrm{~m}$ by $4.6 \mathrm{~m}$, with a $2.2-\mathrm{m}$ high gutter and $3.5-\mathrm{m}$ peak. Whitewash (Kool Ray Classic; Continental Products Co., Euclid, OH) was applied on the glassglazed greenhouse exterior to decrease the light intensity (by $\approx 25 \%$ ) and improve the uniformity of sunlight. In each section, light intensity at bench height was recorded by a quantum sensor (LI-190SA; LI-COR, Lincoln, NE), air temperature by an aspirated thermocouple (Type E; Omega Engineering, Stamford, CT) near canopy height, and leaf canopy temperature by an IR thermocouple (Type K, OS36-01; Omega Engineering) placed $15 \mathrm{~cm}$ above the canopy and oriented downward at a $45^{\circ}$ angle. Environmental conditions in each section were monitored and logged with a data logger (CR-10; Campbell Scientific, Logan, UT) every $10 \mathrm{~s}$ and hourly averages were recorded. The target set point for air temperature was $20^{\circ} \mathrm{C}$ during the day and night. Conditions were maintained by a greenhouse environmental control system (Integro 725; Priva North America, Vineland, Ontario, Canada) that controlled roof vents, exhaust fans, evaporative cooling pads, and steam heating. Environmental data are reported in Table 1.

Lighting treatments. The treatments delivered SL for $16 \mathrm{~h} \cdot \mathrm{d}^{-1}$ (0600 to $2200 \mathrm{HR}$ ) at a $P P F D$ of $90 \mu \mathrm{mol} \cdot \mathrm{m}^{-2} \cdot \mathrm{s}^{-1}$ (five sections) or $10 \mu \mathrm{mol} \cdot \mathrm{m}^{-2} \cdot \mathrm{s}^{-1}$ (one section, which served as a control) as measured at plant height by a portable spectroradiometer (PS-200; Apogee Instruments Inc., Logan, UT) (Fig. 1). In repetitions 1 and 2 , SL was delivered when ambient $P P F D$ was $<185 \mu \mathrm{mol} \cdot \mathrm{m}^{-2} \cdot \mathrm{s}^{-1}$ and switched off when $>370 \mu \mathrm{mol} \cdot \mathrm{m}^{-2} \cdot \mathrm{s}^{-1}$. In repetition 3, SL was delivered for the entire 16-h photoperiod, regardless of ambient $P P F D$. Two of the SL treatments were delivered by HPS lamps with either one 150-W fixture (LU150; Acuity Lithonia Lighting, Conyers, GA) or four 400-W fixtures (LR48877; P.L. Light Systems, Beamsville, Ontario, Canada) to deliver $10 \pm 2$ or $90 \pm 10$ $\mu \mathrm{mol} \cdot \mathrm{m}^{-2} \cdot \mathrm{s}^{-1}$, respectively. The four remaining SL treatments were delivered by $200-\mathrm{W}$ LED fixtures that contained $\mathrm{R}$ (peak $=660 \mathrm{~nm})$, $\mathrm{B}$ (peak $=453 \mathrm{~nm}$ ), or white LEDs (Philips GP-TOPlight DRB-LB2013; Koninklijke Philips N.V., Eindhoven, the Netherlands). The 100-nm waveband ratios of these four LED treatments, defined by their relative amounts of $\mathrm{B}, \mathrm{G}$, and $\mathrm{R}$ light, were $\mathrm{B}_{10} \mathrm{R}_{90}$, $\mathrm{B}_{20} \mathrm{R}_{80}, \mathrm{~B}_{10} \mathrm{G}_{5} \mathrm{R}_{85}$, and $\mathrm{B}_{15} \mathrm{G}_{5} \mathrm{R}_{80}$. The 10 and $90 \mu \mathrm{mol} \cdot \mathrm{m}^{-2} \cdot \mathrm{s}^{-1}$ HPS lamps emitted ratios of $\mathrm{B}_{6} \mathrm{G}_{61} \mathrm{R}_{33}$. Each LED fixture (122 cm long, $5 \mathrm{~cm}$ wide, and $10 \mathrm{~cm}$ tall) contained 10 arrays each consisting of 9 diodes. To achieve the desired $P P F D$, the heights of the HPS lamps and benches were adjusted. In addition, a flexible, neutral-density mesh (General Purpose Aluminum; New York Wire, Grand
Island, NY) enclosed all LED arrays to reduce light intensity by $\approx 35 \%$ without affecting incident solar radiation. Each LED fixture was mounted horizontally $1.9 \mathrm{~m}$ above the bench height and the 400-W and 150-W HPS fixtures were mounted $1.3 \mathrm{~m}$ and $2.5 \mathrm{~m}$ above the plants, respectively. Glass walls between sections were coated with a heavy layer of whitewash to prevent light treatment contamination. With a digital clamp-on current meter (DL379; UEi Test Instruments, Beaverton, OR), power consumption of the SL treatments was obtained by multiplying voltage, current, and the manufacturer-rated power factor of 0.95 . This value was multiplied by the number of hours SL was run per day to estimate power usage in $\mathrm{kWh} \cdot \mathrm{d}^{-1}$.

Common environment. After 14 to $40 \mathrm{~d}$ of lighting treatments (depending on cultivar and seasonal conditions), 10 seedlings (five from each block) of each bedding plant cultivar, (all cultivars except pepper and tomato), from each treatment were transplanted into $10-\mathrm{cm}$ pots containing $70 \%$ peatmoss, $21 \%$ perlite, and $9 \%$ vermiculite (Suremix; Michigan Grower Products Inc., Galesburg, MI). The bedding plants were grown until flowering in a separate common greenhouse environment set at $20^{\circ} \mathrm{C}$ with SL from HPS lamps at a $P P F D$ of $60 \mu \mathrm{mol} \cdot \mathrm{m}^{-2} \cdot \mathrm{s}^{-1}$ for $16 \mathrm{~h}$ (0600 to $2200 \mathrm{HR})$. Lamps were switched on when ambient $P P F D$ was $<185$ $\mu \mathrm{mol} \cdot \mathrm{m}^{-2} \cdot \mathrm{s}^{-1}$ and switched off when $>370$ $\mu \mathrm{mol} \cdot \mathrm{m}^{-2} \cdot \mathrm{s}^{-1}$. Date of first open flower and total number of flowers or inflorescences (old and existing) 7-10 d after flowering were recorded.

Plant measurements and experimental design. The experiment was performed three times, with seed sowings in Jan., Mar., and May 2015. The experimental design was a randomized complete block with subsamples to account for seasonal changes in DLI

Table 1. Means $( \pm \mathrm{SD})$ of greenhouse air temperature, leaf temperature, and photosynthetic daily light integral (DLI) as measured by aspirated thermocouples, infrared sensors, and quantum sensors, respectively, under ambient solar radiation with supplemental lighting treatments delivered by highpressure sodium (HPS) or light-emitting diodes (LEDs). For the LED treatments, subscript values that follow each waveband of blue (B, 400 to $500 \mathrm{~nm}$ ), green (G, 500 to $600 \mathrm{~nm})$, and red (R, 600 to $700 \mathrm{~nm})$ radiation indicate their percentages. Numbers in subscript after HPS treatments denote their intensity $\left(\mu \mathrm{mol} \cdot \mathrm{m}^{-2} \cdot \mathrm{s}^{-1}\right)$. Lighting treatments were provided for 14 to $40 \mathrm{~d}$ depending on cultivar and replication.

\begin{tabular}{|c|c|c|c|c|c|}
\hline $\begin{array}{l}\text { Treatment } \\
\text { initiation }\end{array}$ & $\begin{array}{l}\text { Supplemental } \\
\text { light treatment }\end{array}$ & $\begin{array}{l}\text { Daytime air } \\
\text { temp }\left({ }^{\circ} \mathrm{C}\right)\end{array}$ & $\begin{array}{c}\text { Daytime leaf } \\
\text { temp }\left({ }^{\circ} \mathrm{C}\right)\end{array}$ & $\begin{array}{l}\text { Air - leaf } \\
\text { temp }\left({ }^{\circ} \mathrm{C}\right)\end{array}$ & $\operatorname{DLI}\left(\mathrm{mol} \cdot \mathrm{m}^{-2} \cdot \mathrm{d}^{-1}\right)$ \\
\hline \multirow[t]{6}{*}{ 22 Jan. } & $\mathrm{HPS}_{10}$ & $19.8 \pm 1.1$ & $16.8 \pm 1.5$ & 3.0 & $4.9 \pm 0.5$ \\
\hline & $\mathrm{HPS}_{90}$ & $18.3 \pm 0.6$ & $19.0 \pm 1.5$ & -0.7 & Not recorded \\
\hline & $\mathrm{B}_{10} \mathrm{R}_{90}$ & $19.6 \pm 0.7$ & $18.6 \pm 1.5$ & 1.0 & $7.3 \pm 0.6$ \\
\hline & $\mathrm{B}_{20} \mathrm{R}_{80}$ & $19.8 \pm 0.7$ & $18.2 \pm 1.6$ & 1.6 & $8.5 \pm 0.7$ \\
\hline & $\mathrm{B}_{10} \mathrm{G}_{5} \mathrm{R}_{85}$ & $20.4 \pm 0.8$ & $19.3 \pm 1.2$ & 1.1 & $7.8 \pm 0.5$ \\
\hline & $\mathrm{B}_{15} \mathrm{G}_{5} \mathrm{R}_{80}$ & $21.3 \pm 0.8$ & $19.9 \pm 1.4$ & 1.4 & $7.5 \pm 0.5$ \\
\hline \multirow[t]{6}{*}{5 Mar. } & $\mathrm{HPS}_{10}$ & $21.1 \pm 1.0$ & $19.0 \pm 1.9$ & 2.1 & $7.7 \pm 1.2$ \\
\hline & $\mathrm{HPS}_{90}$ & $20.5 \pm 1.4$ & $21.2 \pm 1.7$ & -0.7 & $8.8 \pm 0.7$ \\
\hline & $\mathrm{B}_{10} \mathrm{R}_{90}$ & $21.2 \pm 0.8$ & $20.6 \pm 1.5$ & 0.6 & $8.8 \pm 0.8$ \\
\hline & $\mathrm{B}_{20} \mathrm{R}_{80}$ & $20.6 \pm 1.7$ & $20.3 \pm 2.1$ & 0.3 & $9.0 \pm 1.0$ \\
\hline & $\mathrm{B}_{10} \mathrm{G}_{5} \mathrm{R}_{85}$ & $20.8 \pm 2.1$ & $19.9 \pm 1.4$ & 0.9 & $8.8 \pm 0.8$ \\
\hline & $\mathrm{B}_{15} \mathrm{G}_{5} \mathrm{R}_{80}$ & $20.5 \pm 1.1$ & $19.7 \pm 1.7$ & 0.8 & $9.1 \pm 0.9$ \\
\hline \multirow[t]{6}{*}{15 Jun. } & $\mathrm{HPS}_{10}$ & $22.9 \pm 2.7$ & $20.7 \pm 3.7$ & 2.2 & $6.4 \pm 1.9$ \\
\hline & $\mathrm{HPS}_{90}$ & $21.9 \pm 3.4$ & $24.5 \pm 4.5$ & -2.6 & $10.5 \pm 1.9$ \\
\hline & $\mathrm{B}_{10} \mathrm{R}_{90}$ & $22.1 \pm 2.4$ & $24.8 \pm 4.7$ & -2.7 & $10.1 \pm 1.9$ \\
\hline & $\mathrm{B}_{20} \mathrm{R}_{80}$ & $22.0 \pm 3.5$ & $24.5 \pm 4.9$ & -2.5 & $11.0 \pm 2.1$ \\
\hline & $\mathrm{B}_{10} \mathrm{G}_{5} \mathrm{R}_{85}$ & $22.1 \pm 2.6$ & $24.4 \pm 5.4$ & -2.3 & $9.8 \pm 2.1$ \\
\hline & $\mathrm{B}_{15} \mathrm{G}_{5} \mathrm{R}_{80}$ & $21.6 \pm 2.8$ & $24.7 \pm 4.5$ & -3.1 & $9.8 \pm 1.9$ \\
\hline
\end{tabular}




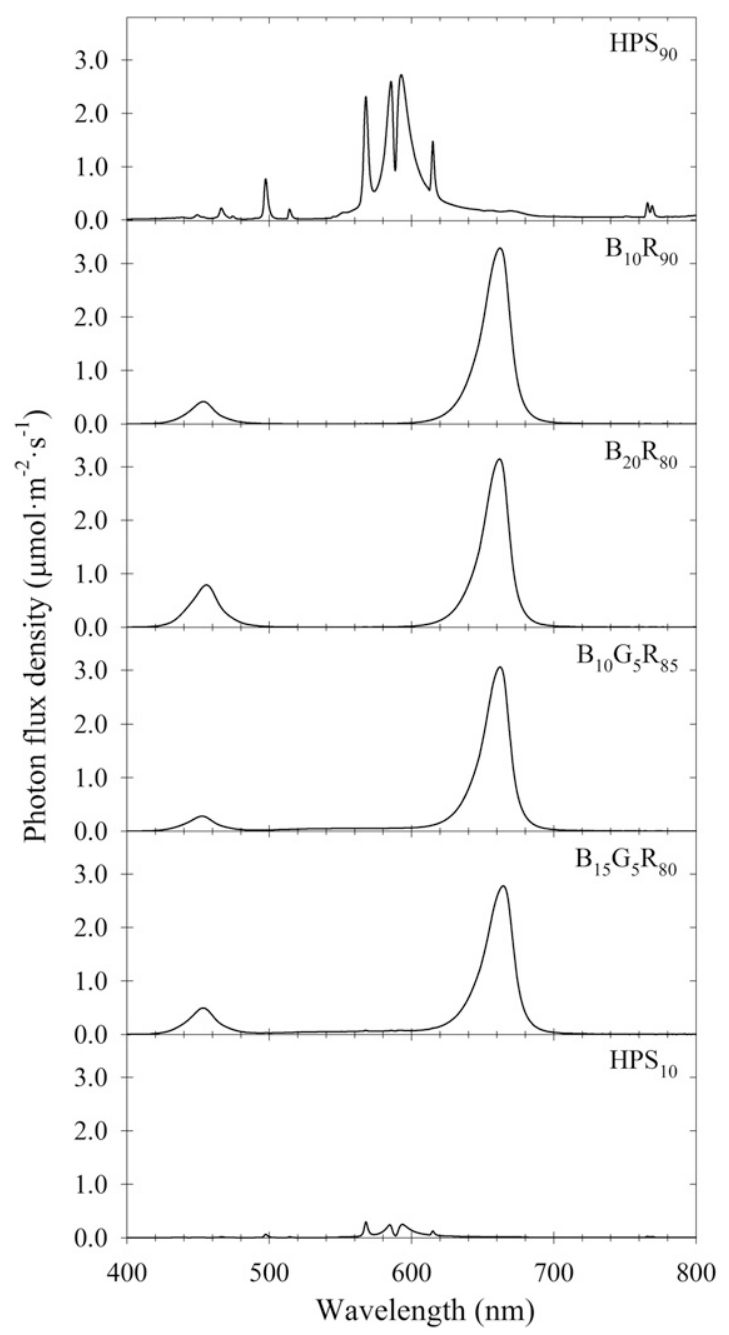

Fig. 1. Spectral distribution of six supplemental lighting treatments between 400 and $800 \mathrm{~nm}$ from highpressure sodium (HPS) and light-emitting diodes (LEDs) delivering different proportions of (B, 400 to $500 \mathrm{~nm}$ ), green (G, 500 to $600 \mathrm{~nm}$ ), and red (R, 600 to $700 \mathrm{~nm}$ ). Numbers in subscript after HPS denote the intensity delivered, in $\mu \mathrm{mol} \cdot \mathrm{m}^{-2} \cdot \mathrm{s}^{-1}$, and the numbers in subscript after the LED treatments denote the percentage of $\mathrm{B}, \mathrm{G}$, and $\mathrm{R}$ in each, which totaled $90 \mu \mathrm{mol} \cdot \mathrm{m}^{-2} \cdot \mathrm{s}^{-1}$.

and temperature, among other factors. At transplant, eight seedlings from each block were sampled at random, excluding those in edge rows, and the following measurements were made: leaf area [with a leaf area meter (LI-3000; LI-COR)], leaf number, and plant height (from substrate surface). Shoots were cut at the medium surface, and roots, separated from the medium in a washbasin, were placed in paper envelopes and into a drying oven (NAPCO 630; NAPCO Scientific Co., Tualatin, OR) at $80{ }^{\circ} \mathrm{C}$ for at least $48 \mathrm{~h}$ and then measured for shoot and root dry weight. Data were analyzed with the mixed-model procedure (PROC MIXED) in SAS (SAS 9.3; SAS Institute, Cary, NC) and pairwise comparisons between treatments were performed with Tukey's honest significant difference test $(P \leq 0.05)$.

\section{Results}

Dry shoot and root weight. None of the seven cultivars showed significant differences in dry shoot weights among the LED
SL treatments and the $\mathrm{HPS}_{90}$ treatment (Fig. 2). Geranium 'PPS', petunia 'SDW', petunia 'WML', snapdragon, and tomato seedlings grown under $\mathrm{HPS}_{10}$ had $37 \%$, $40 \%, 37 \%, 50 \%$, and $27 \%$ less dry shoot weight, respectively, than seedlings grown under $\mathrm{HPS}_{90}$. Dry root weight followed the same trend; petunia 'WML', snapdragon, and tomato seedlings accumulated $42 \%, 51 \%$, and $38 \%$ less dry root weight, respectively, under $\mathrm{HPS}_{10}$ than $\mathrm{HPS}_{90}$. Among 90 $\mu \mathrm{mol} \cdot \mathrm{m}^{-2} \cdot \mathrm{s}^{-1}$ treatments, six of seven cultivars had similar dry root weights. Tomato seedlings grown under the $\mathrm{B}_{20} \mathrm{R}_{80}$ LED $\mathrm{SL}$ treatment had $23 \%$ greater dry root weight than those grown under the $\mathrm{B}_{10} \mathrm{R}_{90}$ LED SL treatment, whereas all others were statistically similar.

Plant height. There were no differences in plant height of seedlings grown under any of the SL lighting treatments for five of seven cultivars (Fig. 3). Snapdragon seedlings grown under $\mathrm{HPS}_{10}$ were $33 \%$ shorter than those grown under $\mathrm{HPS}_{90}$, but were not significantly shorter than those grown under any LED SL treatment. Pepper seedlings grown under the $\mathrm{B}_{15} \mathrm{G}_{5} \mathrm{R}_{80}$ LED SL treatment were $24 \%, 32 \%$, and $34 \%$ taller than seedlings grown under the $\mathrm{B}_{10} \mathrm{R}_{90}, \mathrm{~B}_{20} \mathrm{R}_{80}$, and $\mathrm{B}_{10} \mathrm{G}_{5} \mathrm{R}_{85}$ LED SL treatments, respectively, but were not different from those grown under either HPS SL treatment.

Leaf area. In the seven cultivars tested, only pepper showed a response to the SL treatments with respect to leaf area. Pepper plants grown under $\mathrm{B}_{15} \mathrm{G}_{5} \mathrm{R}_{80}$ LED SL had greater leaf area than plants grown under the $\mathrm{B}_{20} \mathrm{R}_{80}$ and $\mathrm{B}_{10} \mathrm{G}_{5} \mathrm{R}_{85}$ LED treatments. However, plants under these two LED treatments were similar to those in the remaining three LED treatments.

Leaf number. In general, seedlings grown under $\mathrm{HPS}_{10}$ had a similar number or fewer leaves than those under the $90 \mu \mathrm{mol} \cdot \mathrm{m}^{-2} \cdot \mathrm{s}^{-1}$ treatments at transplant, but there were few consistent differences among leaf number under $90 \mu \mathrm{mol} \cdot \mathrm{m}^{-2} \cdot \mathrm{s}^{-1}$ treatments (Fig. 4). In geranium 'PPS', seedlings under $\mathrm{HPS}_{10}$ had 4.0 leaves at transplant compared with 4.4 and 4.5 for seedlings grown under $\mathrm{HPS}_{90}$ and $\mathrm{B}_{20} \mathrm{R}_{80}$ LED SL, respectively. In petunia 'WML', seedlings grown under $\mathrm{B}_{10} \mathrm{R}_{90}$ and $\mathrm{B}_{15} \mathrm{G}_{5} \mathrm{R}_{80}$ LED SL had more leaves on average (7.9 and 8.1, respectively) than seedlings grown under HPS $_{10}$ (6.9). Tomato seedlings grown under $\mathrm{HPS}_{10}$ had fewer leaves than seedlings grown under $B_{20} R_{80}$, but there were no other differences between treatments. There were fewer leaves on pepper seedlings grown under $\mathrm{B}_{10} \mathrm{G}_{5} \mathrm{R}_{85}$ LED SL than those under $B_{15} G_{5} R_{80}$ LED SL (4.1 to 5.3, respectively). Again, there were no other differences between treatments.

Days to flower and total flower number. In all cultivars tested, time to flower and total flower or inflorescence number were similar when seedlings were grown under 90 $\mu \mathrm{mol} \cdot \mathrm{m}^{-2} \cdot \mathrm{s}^{-1}$ SL from either HPS or LEDs (Fig. 5). Transplants of geranium 'RDS' and petunia 'SDW' grown under $90 \mu \mathrm{mol} \cdot \mathrm{m}^{-2} \cdot \mathrm{s}^{-1}$ HPS SL flowered $3 \mathrm{~d}$ earlier than those grown under $\mathrm{HPS}_{10}$, and snapdragons had $30 \%$ more inflorescences when grown under 90 $\mu \mathrm{mol} \cdot \mathrm{m}^{-2} \cdot \mathrm{s}^{-1}$ HPS or $\mathrm{B}_{15} \mathrm{G}_{5} \mathrm{R}_{80}$ LED SL compared with $\mathrm{HPS}_{10}$.

\section{Discussion}

We included the $10 \mu \mathrm{mol} \cdot \mathrm{m}^{-2} \cdot \mathrm{s}^{-1} \mathrm{SL}$ treatment to provide the same photoperiod as the higher-intensity treatments. Depending on the season and ambient conditions, the 90 $\mu \mathrm{mol} \cdot \mathrm{m}^{-2} \cdot \mathrm{s}^{-1} \mathrm{SL}$ treatments provided an additional 1.4 to $4.6 \mathrm{~mol} \cdot \mathrm{m}^{-2} \cdot \mathrm{d}^{-1}$ (Table 1 ), which increased the total DLI by $16 \%$ to $40 \%$. An increase in DLI through SL can have positive effects on transplant growth and quality of floriculture crops (Pramuk and Runkle, 2005; Randall and Lopez, 2015; Torres and Lopez, 2011). Pramuk and Runkle (2005) reported a linear increase in shoot dry weight per internode as DLI increased from 4.1 to $14.2 \mathrm{~mol} \cdot \mathrm{m}^{-2} \cdot \mathrm{d}^{-1}$ in celosia 'Gloria Mix', impatiens 'Accent Red', marigold 'Bonanza Yellow', and viola 'Crystal Bowl Yellow'. An increase in shoot dry weight per 

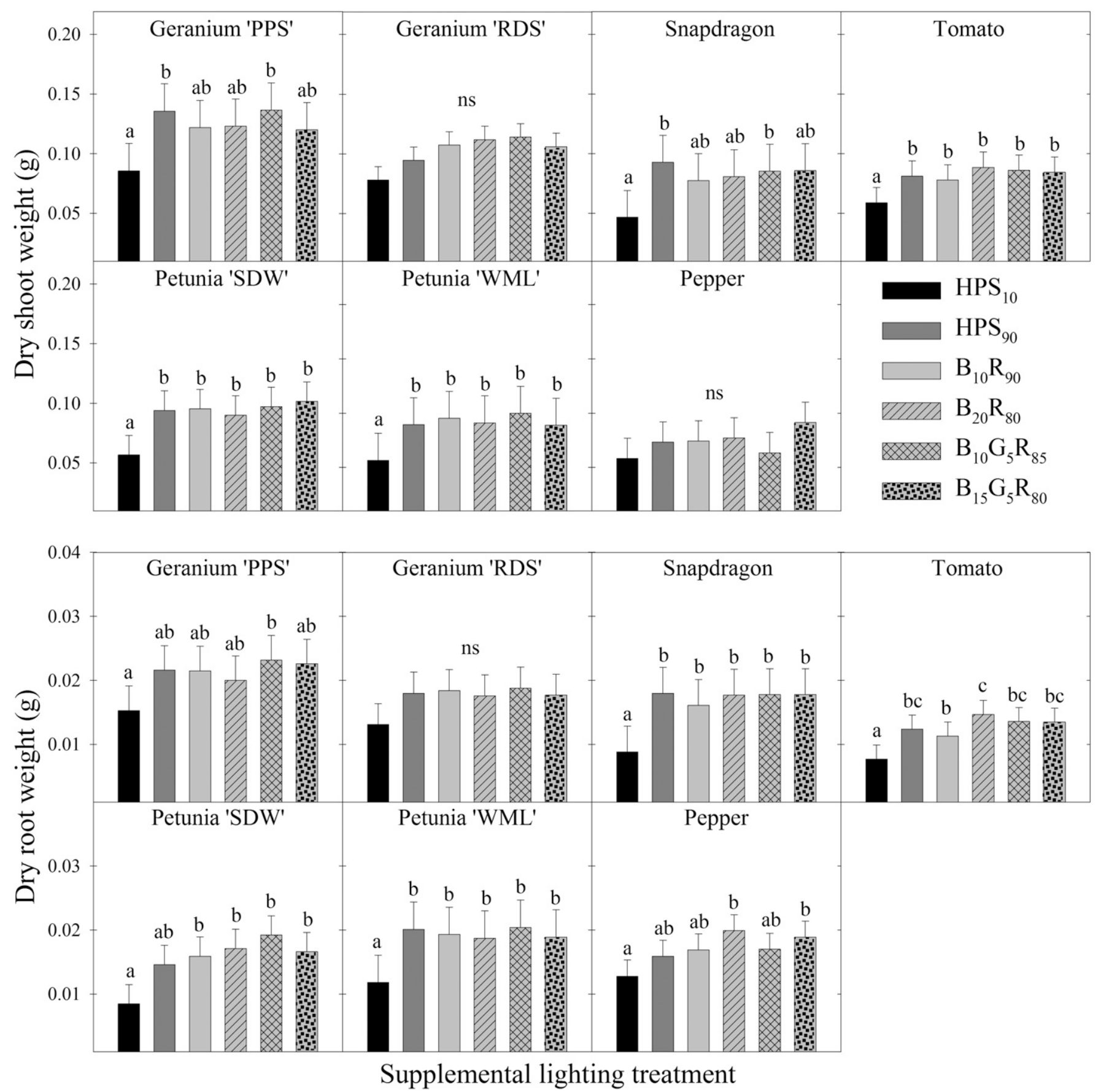

Fig. 2. Dry shoot and root weights of seven seedling cultivars grown under ambient light and supplemental lighting from two high-pressure sodium (HPS) or four light-emitting diode (LED) treatments delivering different proportions of blue (B, 400 to $500 \mathrm{~nm}$ ), green (G, 500 to $600 \mathrm{~nm}$ ), and red (R, 600 to $700 \mathrm{~nm})$. All treatments were delivered at a photosynthetic photon flux density of $90 \mu \mathrm{mol} \cdot \mathrm{m}^{-2} \cdot \mathrm{s}^{-1}$, except $\mathrm{HPS}_{10}$, which was delivered at $10 \mu \mathrm{mol} \cdot \mathrm{m}^{-2} \cdot \mathrm{s}^{-1}$. Numbers in subscript of LED treatments denote proportion of intensity in 100-nm wavebands. Means sharing a letter are not statistically different by Tukey's honest significant difference test at $P \leq 0.05$. Error bars indicate standard error. 'PPS' = 'Pinto Premium Salmon'; 'RDS' = 'Ringo 2000 Deep Scarlet'; 'SDW' = 'Single Dreams White'; 'WML' = 'Wave Misty Lilac'.

internode also occurred in salvia 'Vista Rose' but reached a maximum as DLI reached 12 $\mathrm{mol} \cdot \mathrm{m}^{-2} \cdot \mathrm{d}^{-1}$. Similarly, in our experiment, the increased DLI from SL at $90 \mu \mathrm{mol} \cdot \mathrm{m}^{-2} \cdot \mathrm{s}^{-1}$ increased shoot dry weight in petunia 'SDW', petunia 'WML', and tomato, regardless of delivery from HPS or LED fixtures, compared with $10 \mu \mathrm{mol} \cdot \mathrm{m}^{-2} \cdot \mathrm{s}^{-1} \mathrm{SL}$. The maximum recorded DLI was $11.0 \mathrm{~mol} \cdot \mathrm{m}^{-2} \cdot \mathrm{d}^{-1}$, and we did not observe a negative effect of increased DLI on shoot dry weight in any cultivar or treatment.
Randall and Lopez (2015) observed an increase in shoot dry weight of seedlings grown under SL or SSL (providing a DLI of 10.4 to $10.9 \mathrm{~mol} \cdot \mathrm{m}^{-2} \cdot \mathrm{d}^{-1}$ ) compared with those grown under ambient light with a DLI of 6.3 to $6.7 \mathrm{~mol} \cdot \mathrm{m}^{-2} \cdot \mathrm{d}^{-1}$. Seedlings of vinca 'Titan Red Dark', impatiens 'Super Elfin XP Blue Pearl', geranium 'Bullseye Red', petunia 'Dreams Purple', and marigold 'Durango Yellow' had $50 \%$ to $164 \%$ greater dry weight when grown under SL or SSL compared with that of those grown under ambient light alone. The consistent increase in shoot dry weight of all species they tested, which was not as common in our experiment, could be species or cultivar specific or attributed to the greater difference in DLI between ambient and SL treatments in their study. SL increased the DLI by $\geq 37 \%$ in the study by Randall and Lopez (2015) while in this study, SL increased the DLI by $\leq 37 \%$. As did Randall and Lopez (2015), Hernandez and 

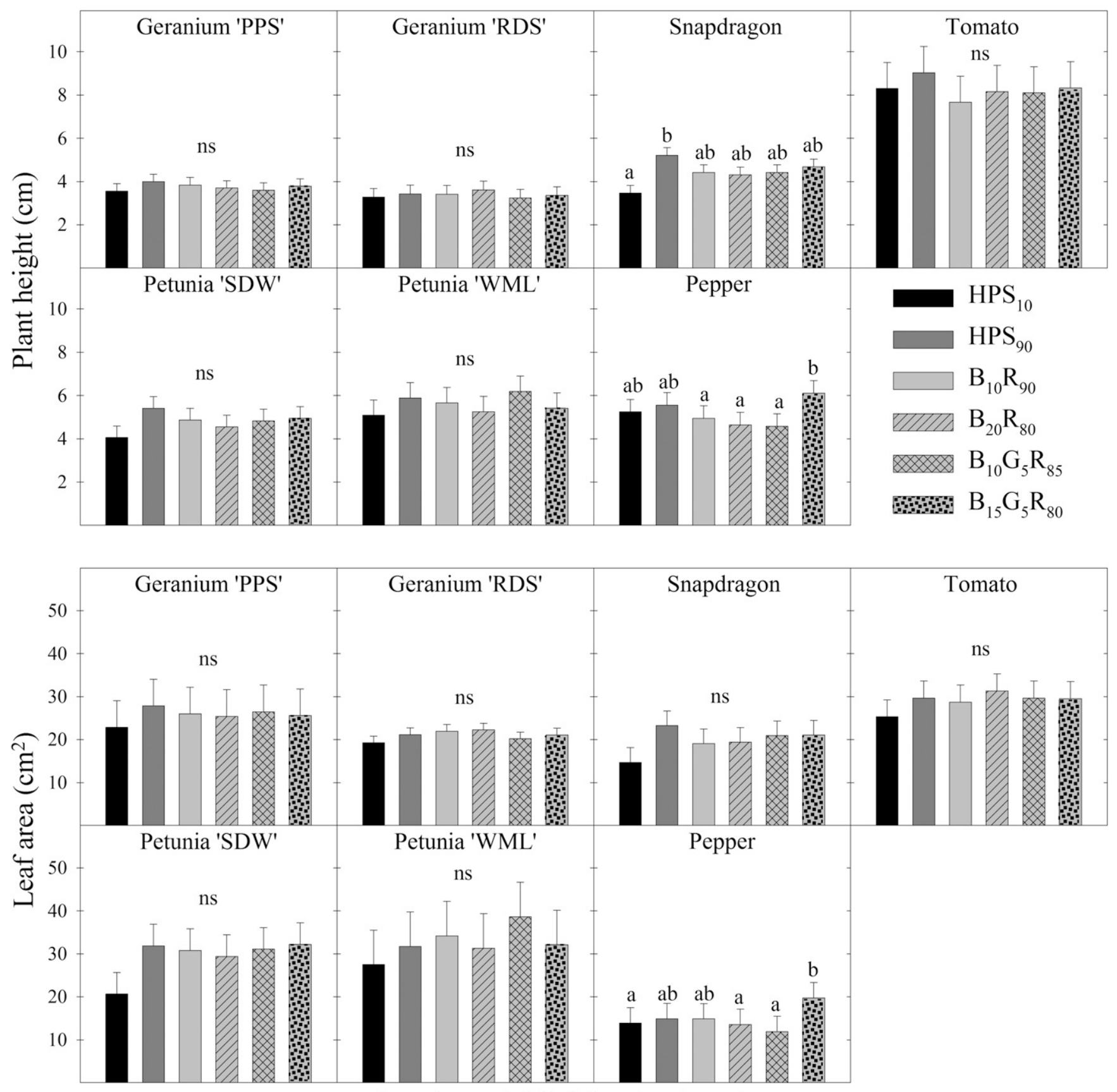

Supplemental lighting treatment

Fig. 3. Plant height and leaf area of seven seedling cultivars grown under ambient light and supplemental lighting from two high-pressure sodium (HPS) or four light-emitting diode (LED) treatments delivering different proportions of blue (B, 400 to $500 \mathrm{~nm}$ ), green (G, 500 to $600 \mathrm{~nm}$ ), and red (R, 600 to $700 \mathrm{~nm}$ ). See caption for Fig. 2 for treatment information and cultivar abbreviations.

Kubota (2014) reported that tomato and cucumber seedlings grown under LED SL had $47 \%$ and $39 \%$ more shoot dry weight, respectively, compared with those grown under ambient light alone, which can be attributed to a $22 \%$ and $67 \%$ increase, respectively, in DLI from SL.

Previous experiments also showed that an increase in DLI during seedling production can reduce subsequent time to flower after transplant. Pramuk and Runkle (2005) reported that time to flower of celosia and salvia was reduced by $24 \%$ and $41 \%$ as DLI increased from 4.1 to $14.2 \mathrm{~mol} \cdot \mathrm{m}^{-2} \cdot \mathrm{d}^{-1}$, respectively, whereas time to flower of marigold, viola, and impatiens was reduced by $19 \%$ to $33 \%$ as DLI increased from 4.1 to 11 $\mathrm{mol} \cdot \mathrm{m}^{-2} \cdot \mathrm{d}^{-1}$. Randall and Lopez (2015) reported reduced time to flower for vinca and geranium transplants grown under HPS SL during the seedling phase compared with that of those grown under ambient light alone. Their results were slightly different for seedlings grown under $B_{13} R_{87}$ LED SL, in which time to flower was reduced for geranium and petunia seedlings compared with that for those under ambient light. As did Randall and Lopez (2015), we observed very few differences in time to flower in any plants grown under SL from HPS or LEDs during the seedling phase compared with the HPS 10 treatment.

The HPS lamp is the most common type used by commercial greenhouse growers in temperate climates. Our experimental objective was to quantify and compare growth and morphological characteristics of seedlings grown under HPS and LED SL. Few comparative studies focusing on the use of HPS and LED SL for seedling production have been published. Randall and Lopez (2014) compared growth and quality of nine bedding 


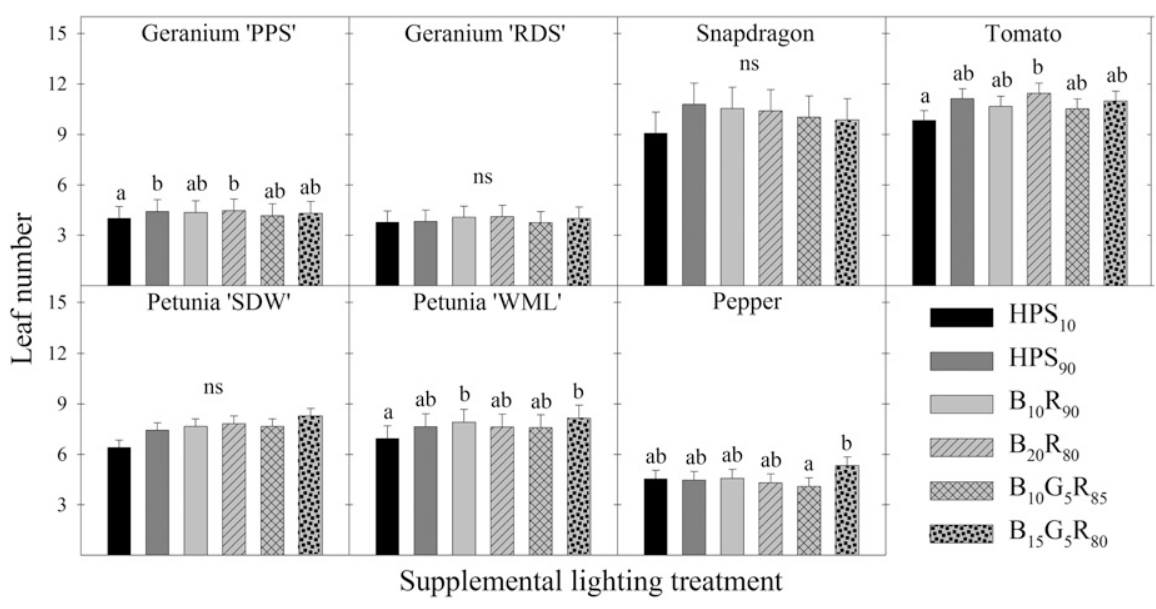

Fig. 4. Leaf number at transplant of seven seedling cultivars grown under ambient light and supplemental lighting from two high-pressure sodium (HPS) or four light-emitting diode (LED) treatments delivering different proportions of blue (B, 400 to $500 \mathrm{~nm}$ ), green $(\mathrm{G}, 500$ to $600 \mathrm{~nm})$, and red (R, 600 to $700 \mathrm{~nm}$ ). See caption for Fig. 2 for treatment information and cultivar abbreviations.
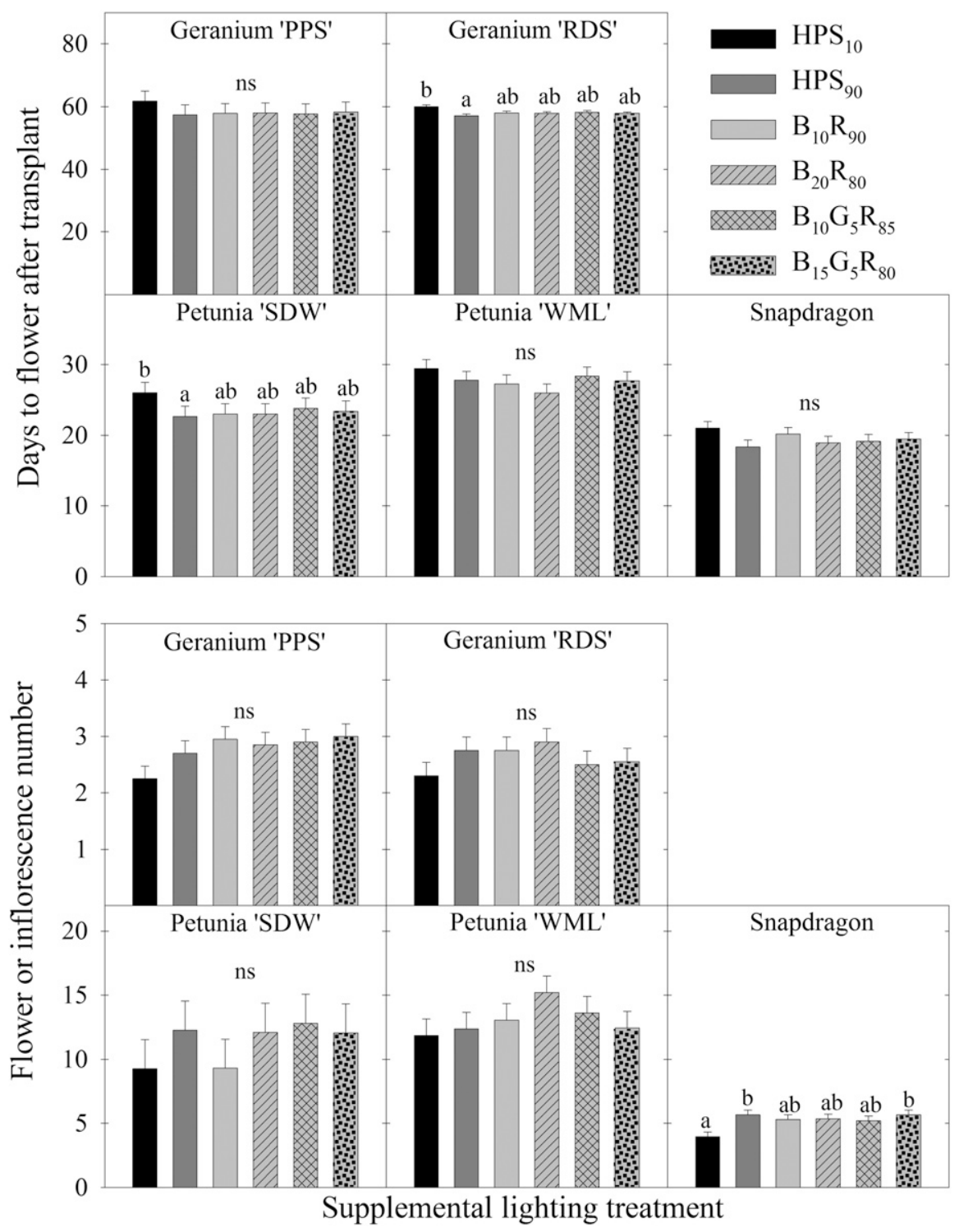

Fig. 5. Days to flower after transplant and total flower or inflorescence number (old and existing) 7-10 d after flowering of seven seedling cultivars grown under ambient light and supplemental lighting from two high-pressure sodium (HPS) or four light-emitting diode (LED) treatments delivering different proportions of blue (B, 400 to $500 \mathrm{~nm}$ ), green $(\mathrm{G}, 500$ to $600 \mathrm{~nm}$ ), and red (R, 600 to $700 \mathrm{~nm}$ ). See caption for Fig. 2 for treatment information and cultivar abbreviations. plant species grown under ambient light with $100 \mu \mathrm{mol} \cdot \mathrm{m}^{-2} \cdot \mathrm{s}^{-1}$ of SL from either HPS or LEDs providing $100 \% \mathrm{R}, 85 \% \mathrm{R}$ and $15 \% \mathrm{~B}$, or $70 \% \mathrm{R}$ and $30 \% \mathrm{~B}$ for $16 \mathrm{~h} \cdot \mathrm{d}^{-1}$. In four species, there were no differences in shoot dry weight between seedlings grown under HPS or LED SL, but seedlings of impatiens, petunia, salvia, and viola had $18 \%, 25 \%$, $24 \%$, and $40 \%$ less shoot dry weight, respectively, when grown under $70 \% \mathrm{R}$ and $30 \%$ B LED SL compared with those grown under HPS SL. Additionally, celosia seedlings grown under any of the LED treatments had reduced shoot dry weight compared with those grown under HPS SL. Furthermore, Randall and Lopez (2015) reported that impatiens and marigold grown under LED SL providing $13 \% \mathrm{~B}$ and $87 \% \mathrm{R}$ had less shoot dry weight compared with seedlings grown under HPS SL. We, however, did not observe any differences in shoot dry weight among seedlings grown under any 90 $\mu \mathrm{mol} \cdot \mathrm{m}^{-2} \cdot \mathrm{s}^{-1}$ SL treatment.

When seedling height at transplant was compared, eight of nine species were shorter when grown under LED SL containing B light compared with those grown under HPS SL (Randall and Lopez, 2014). Randall and Lopez (2015) also reported shorter seedlings in five species tested when grown under B-containing LED SL treatments compared with seedlings grown under HPS SL. In the seven cultivars we tested, there were no differences in height at transplant between $90 \mu \mathrm{mol} \cdot \mathrm{m}^{-2} \cdot \mathrm{s}^{-1}$ LED and HPS SL treatments. The percentage of DLI provided by SL could explain the difference in results between these studies. Supplemental light provided $\approx 20 \%$ to $40 \%$ of the DLI in our study, whereas SL provided $40 \%$ to $70 \%$ in the studies by Randall and Lopez (2014, 2015). The smaller proportion of DLI coming from the SL treatments likely reduced any spectral effects on our study because solar radiation likely contains enough $\mathrm{B}$ photons to saturate any morphological effects (Hernandez and Kubota, 2014).

The inclusion of B with R LEDs in SSL can decrease seedling height. In a study by Wollaeger and Runkle (2014), delivering up to $50 \%$ B light with $\mathrm{R}$ LED treatments reduced height in impatiens, tomato, and salvia seedlings compared with seedlings grown under $100 \% \mathrm{R}$ light from LEDs. The authors attributed the reduction in height to B-light-mediated cryptochrome stem extension inhibition. We did not observe any consistent SL treatment effects on seedling height; five of seven cultivars showed no difference in height under any SL treatment with B light percentages of $10 \%$ to $20 \%$, regardless of intensity. However, pepper plants grown under the $\mathrm{B}_{15} \mathrm{G}_{5} \mathrm{R}_{80}$ LED treatment were significantly taller than seedlings grown under the other LED SL treatments. This is in contrast with other SL studies in which $15 \% \mathrm{~B}+85 \% \mathrm{R}$ decreased height (Randall and Lopez, 2014, 2015). As mentioned earlier, the proportion of the DLI provided by the SL treatments $(\approx 16 \%$ to $40 \%$ ) in our study was likely not sufficient 
to elicit morphological changes as reported in the other experiments. Therefore, we postulate that to elicit photomorphogenic responses in a greenhouse, B light from SL must be more pronounced (e.g., $\geq 50 \% \mathrm{~B}$ light), the proportion of the DLI from SL must be greater, or both.

It is a misconception that LEDs are universally more efficient than conventional broad-band SL systems. Nelson and Bugbee (2014) tested the electrical efficiencies (efficacy) of five lamp types and reported that the two most effective HPS fixtures (doubleended, electronic ballast) were similar to the most effective LEDs available at that time $\left(1.7 \mu \mathrm{mol} \cdot \mathrm{J}^{-1}\right)$. Of the 10 LED modules tested, two had lower photon efficiencies than the 400-W HPS fixture with a magnetic ballast rated at $0.9 \mu \mathrm{mol} \cdot \mathrm{J}^{-1}$. In our experiment, the daily usage of the HPS ${ }_{90}, B_{10} R_{90}$, $\mathrm{B}_{20} \mathrm{R}_{80}, \mathrm{~B}_{10} \mathrm{G}_{5} \mathrm{R}_{85}$, and $\mathrm{B}_{15} \mathrm{G}_{5} \mathrm{R}_{80}$ treatments were 24.3, 17.3, 17.0, 17.8, and 17.3 $\mathrm{kWh} \cdot \mathrm{d}^{-1}$, respectively (data not shown). Therefore, the LED fixtures used $\approx 30 \%$ less power to provide the same $P P F D$ in these small greenhouse compartments. When factoring in the decreased distance between the HPS fixtures and bench compared with the LED fixtures (1.3 $\mathrm{m}$ and $2.5 \mathrm{~m}$, respectively), and that the LEDs were shaded to deliver the same PPFD, the LED modules used in this research were much more effective than the older magnetic ballast HPS fixtures. Using manufacturer data for output efficacy, 2.0$2.3 \mu \mathrm{mol} \cdot \mathrm{J}^{-1}$ (Philips Horticulture LED Solutions, 2015), and subsequently confirmed by Nelson and Bugbee (2014; see reader comments on 18 Aug. 2016), the LED modules used in our experiment were roughly 2.4 times more efficient than the $400-\mathrm{W}$ magnetic ballast HPS fixture and 1.4 times more efficient than the 1000-W double-ended, electronic ballast HPS fixture tested by Nelson and Bugbee (2014).

The emission of radiant heat from HPS lamps can influence the heat load on a crop canopy. Faust and Heins (1997) reported increases of $1.2,1.5$, and $1.7{ }^{\circ} \mathrm{C}$ on vinca shoot-tip temperature relative to air temperature under PPFD treatments of 50,75, and $100 \mu \mathrm{mol} \cdot \mathrm{m}^{-2} \cdot \mathrm{s}^{-1}$, respectively, provided by four $400-W$ HPS lamps. We observed a similar increase in leaf temperature relative to air temperature under the HPS $_{90}$ treatment (but not in the LED treatments) in two replications (Table 1). In the third replication, when the natural photoperiod was much longer and light intensity was greater, leaf temperature relative to air temperature was higher under all treatments except HPS $_{10}$. However, differences in temperature among treatments were apparently not sufficiently different to influence growth rate.

Compact seedlings that have a high dry weight per internode or are otherwise compact are considered more desirable for shipping and successful transplant. In accordance with previous experiments raising seedlings under LED SSL, we expected more compact seedlings by delivering $\mathrm{B}$ and $\mathrm{R}$ light, as observed by Wollaeger and Runkle (2014); however, in our experiment there were no consistent differences in dry matter accumulation or height with different proportions of $\mathrm{B}$ light. Additionally, there were few differences between seedlings grown under HPS and LED SL, and there were no measurable differences in time to flower after transplanting seedlings to a common environment. We conclude that the difference in spectra provided by the HPS and LED SL treatments was not enough to elicit large morphological changes in seedlings grown in our ambient greenhouse light conditions. Future research could focus on the ambient solar conditions or DLI that could enable the spectra evaluated to elicit significant effects on plant morphology, or on modifying the spectra of the treatments to include substantially more B light.

\section{Literature Cited}

Currey, C.J., V.A. Hutchinson, and R.G. Lopez. 2012. Growth, morphology, and quality of rooted cuttings of several herbaceous annual bedding plants are influenced by photosynthetic daily light integral during root development. HortScience 47:25-30.

Faust, J.E. and R.D. Heins. 1997. Quantifying the influence of high-pressure sodium lighting on shoot-tip temperature. Acta Hort. 418:85-91

Fisher, P. and E. Runkle. 2004. Managing light in the greenhouse-Why is it important, p. 9-17. In: P. Fisher and E. Runkle (eds.). Lighting up profits: Understanding greenhouse lighting. Meister Media Worldwide, Willoughby, $\mathrm{OH}$.

Goins, G.D., N.C. Yorio, M.M. Sanwo, and C.S. Brown. 1997. Photomorphogenesis, photosynthesis, and seed yield of wheat plants grown under red light-emitting diodes (LEDs) with and without supplemental blue lighting. J. Expt. Bot. 48:1407-1413.

Hernandez, R. and C. Kubota. 2014. Growth and morphological response of cucumber seedlings to supplemental red and blue photon flux ratios under varied solar daily light integrals. Sci. Hort. 173:92-99.

Hogewoning, S.W., G. Trouwborst, H. Maljaars, H. Poorter, W. van Ieperen, and J. Harbinson. 2010. Blue light dose-responses of leaf photosynthesis morphology, and chemical composition of Cucumis sativus grown under different combinations of red and blue light. J. Expt. Bot. 61:3107-3117.

Korczynski, P.C., J. Logan, and J.E. Faust. 2002. Mapping monthly distribution of daily light integrals across the contiguous United States. HortTechnology 12:12-16.

Lopez, R.G. and E.S. Runkle. 2008. Photosynthetic daily light integral during propagation influences rooting and growth of cuttings and subsequent development of New Guinea impatiens and petunia. HortScience 43:20522059.

Mitchell, C.A., M.P. Dzakovich, C. Gomez, R. Lopez, J.F. Burr, R. Hernaìndez, C. Kubota, C.J. Currey, Q. Meng, E.S. Runkle, C.M. Bourget, R.C. Morrow, and A.J. Both. 2015. Light-emitting diodes in horticulture. Hort. Rev. 43:1-87.

Morrow, R.C. 2008. LED lighting in horticulture. HortScience 43:1947-1950.

Nelson, J.A. and B. Bugbee. 2014. Economic analysis of greenhouse lighting: Light-emitting diodes vs. high intensity discharge fixtures. PLoS One 9(6): 99010.

Philips Horticulture, LED Solutions. 2015. Technical datasheet: GreenPower LED Toplighting. 10 May 2016. $<\mathrm{http}: / /$ www.usa.lighting.philips. $\mathrm{com} /$ products/horticulture.html .

Pramuk, L.A. and E.S. Runkle. 2005. Photosynthetic daily light integral during the seedling stage influences subsequent growth and flowering of Celosia, Impatiens, Salvia, Tagetes, and Viola. HortScience 40:1336-1339.

Randall, W.C. and R.G. Lopez. 2014. Comparisons of supplemental lighting from high-pressure sodium lamps and light-emitting diodes during bedding plant seedling production. HortScience 49:589-595.

Randall, W.C. and R.G. Lopez. 2015. Comparisons of bedding plant seedlings grown under solesource light-emitting diodes (LEDs) and greenhouse supplemental lighting from LEDs and high-pressure sodium lamps. HortScience 50: 705-713

Torres, A.P. and R.G. Lopez. 2011. Photosynthetic daily light integral during propagation of Tecoma stans influences seedling rooting and growth. HortScience 46:282-286.

U.S. Dept. of Agriculture (USDA). 2016. Floriculture crops 2015 summary. Nat. Agr. Stat. Service, Washington, DC.

Wollaeger, H.M. and E.S. Runkle. 2014. Growth of impatiens, petunia, salvia, and tomato seedlings under blue, green, and red light-emitting diodes. HortScience 49:734-740. 